\title{
INFLUENCE OF TEACHERS' TEACHING EXPERIENCE ON TEACHING OF LITERACY SKILLS AMONG GRADE ONE PUPILS IN MOMBASA, KENYA
}

\author{
Emelda Juma Olandoi, \\ Margaret Mwangi \\ Department of Early Childhood \\ and Special Needs Education, \\ Kenyatta University, \\ Nairobi, Kenya
}

\begin{abstract}
:
Early childhood years are crucial in children's literacy development since the development of language and literacy begins at birth and is a lifelong process. For early childhood education to be a success, teacher experience is imperative for teaching literacy. The teachers' experience informs the necessary literacy skills for the child which include writing, reading, speaking, listening and drawing. Policies governing basic education in Kenya do emphasize the importance of skilled, experienced teachers in the classroom, including early childhood settings. However, such requirements have not been adhered to and therefore numerous early childhood teachers lack experience in children literacy issues. This study sought to determine how teacher's experience influences the teaching of literacy skills in primary school in Mbaraki Zone, Mombasa County, Kenya. Descriptive survey design was adopted in the study. The target population for the study comprised of 20 head teachers, 800 Grade one pupils and 40 Grade one teachers of all the twenty primary schools in Mbaraki Zone, Mombasa County, Kenya. Purposive sampling approach was used to obtain the sample for the primary school head teachers and Grade one teachers because they are relatively small. Three learners were sampled randomly from each class that had a participating teacher. The study findings revealed that majority of teachers had more than five years of experience teaching literacy skills. The inferential analysis revealed that the teaching experience had a statistically significant influence on reading ( $p$ 0.014), speaking ( $p$ 0.021), listening skills ( $p$ 0.038) as well as basic skills ( $p$ 0.019). The study calls on the ministry of education and the schools to ensure that teachers assigned to grade one should have extensive experience teaching literacy skills to promote teaching of literacy skills in the classes.
\end{abstract}

Keywords: early childhood, influence, teaching, experience and literacy

${ }^{i}$ Correspondence: email jumaemelda@gmail.com 


\section{Introduction}

Primary school is an important center where a child is given an orientation to the formal learning process. Hopps-Wallis and Perry (2017) point out that the sole objective of primary school education is to orient the child to formal learning and guide them on the acquisition of literacy skills. Early reading and writing are very essential in expanding the development of a different dimension of knowledge. This has resulted in a wide attention geared towards literary skills in the past decades. The early stages of an individual's life, mostly between the ages of three to six years, is a crucial period the development of literacy skills for lifelong edification. During the early period of life, the foundation for the future is made as the child develops the aptitude and establishment to formal learning (Kolb, 2014). If children are not well grounded in this period, it may create difficulties for them during the process of formal learning and may end up not being at the same level of literacy skills development, thus adversely affecting schooling and general academic achievement in subsequent levels. There is, therefore, a need for the development of early literacy skills as it may affect orientation to formal learning. Wildova and Kropáčková, (2015) observed that a child is able to develop a positive relationship to reading and writing speeches if they receive appropriate exposure to learning in the early stages of life. Teacher factors such as teachers' experience are crucial for literacy development (Hamre, Hatfield, Pianta, \& Jamil, 2014). Wildova and Kropáčková, (2015) contends that teacher experience is therefore likely to affect their teaching which may consequently lead to poor academic performance of pupils.

Globally, early childhood education currently focuses more on the quality of the literacy and numeracy skills. For instances, the personality-orientated model has been advocated for in the Czech Republic and other European countries (Opletalová, 2015). The model is made up of five personality factors to facilitate the understanding of the patterns of behavior, feelings and thoughts. The traits constituting to the personalityoriented model are extraversion, neuroticism, agreeableness, openness to experience and conscientiousness. The personality-oriented model is crucial for the current study as the view comes from the argument that each child is unique as an individual who possess talents, abilities, motivation and means of learning inherent to him or her. Therefore, the model utilizes the individual approach in the edification process and in the rearing of each and every child.

Wambiri (2015) opined that when there is lack of sufficient reading foundation, then the children are more likely to face challenges in their reading development and in subsequent levels of learning. Reading achievement in Kenya had been casted doubts as the reading skills among the children in primary school was found to be poor. Ogetange and Murungi (2017) reiterated that reading is basic skill useful throughout one's life and is a cornerstone for learner's accomplishment in school. The two posit that in Kenya, the majority of lower primary school learners' reading abilities are below par. They found that the teacher's approach to teaching reading is often whole word through look and say, rather than the most effective method of phonic approach and direct instructional 
method which support improved reading skills. Mwoma (2017) was of the opinion that good performance and overall academic outcomes depend on the ability of learners to read. She argues that teaching early years how to read is critical for later acquisition of advanced reading and learning skills. Failure to effectively teach reading in the early grades may lead to struggles in acquiring advanced reading skills that are necessary for acquiring concepts in other learning areas.

Aga Khan Foundation (2012) indicated that literacy levels in primary schools in Mombasa County were low which results in poor performance among the children. As has been reiterated by several authors including Mwoma (2017); Ongetange and Murungi (2017) and Jones, Greenberg and Crowley (2015), acquisition of reading skills in early years is critical for the learner's future comprehension of reading materials and success in life. However, despite the importance of ensuring that the learners gain the necessary literacy skills in early years, there is no evidence of outcomes to show that efforts towards improved learner's reading skills are effective. Early years learning should promote development of language and literacy skills, but as evidenced by the continued dismal levels of reading skills among learners, it is evident that there is a major issue in literacy teaching and learning in early years. The reports by Uwezo (2011) show that instructor related dynamics may be contributing to the low literacy expertise among early years pupils. Therefore, there was need to investigate how teachers' experience may be contributing to the low literacy levels among grade one pupils in Mombasa County.

\section{Literature Review}

Reid and Weiser (2009) reported that, for early childhood education to be a success, teacher factors are imperative for literacy development. Teacher factors informs the necessary literacy skills for children, which include: writing, reading, speaking, listening and drawing. These skills are fundamental for their academic achievement. Teaching experience informs the teacher's ability and capacity to disseminate knowledge and skills to learners. With experience, the teacher is exposed to a dynamic situation that requires a concise decision for learning progress to be made. Through the interaction with various learners at different learning opportunities, a teacher is able to evaluate the pupils and understand their underlying problems. Teachers are able to improve on their content, teaching methods and solving problems when they continuously engage in teaching. Bearing in mind that prior exposure can be inferred and may be useful for teachers when disseminating new knowledge to the pupils. Their confidence is always improved with the exposure and experience they acquire (Dana, 2014). In this context, teacher's teaching experience can play a significant role in decision making and content delivery especially the literacy skill.

Ewetan (2015) undertook a study whereby he aimed to identify the effects of teacher's experience on the academic performance of students from public secondary schools in Mathematics and English in various local government areas of Ogun State. To complete their research purpose, the researcher adopted an inventory schedule as the 
preferred data collection tool. From the findings, it was established that the teaching experience that teachers possessed had a significant influence on how students performed academically in the two subjects under examination. This was measured using their performance in the senior certificate examinations as well as per the perceptions of those who partook in the study. Further, the researcher established that as teachers got more teaching experience, they tended to achieve better results as compared to the schools where their teachers were still new to their careers and had accumulated less teaching experience. The study, however, cannot be generalized to the current context as the researcher targeted secondary school students whereas the current study focused on grade one learners.

Chokera (2014) purposed to determine how the different characteristics inherent to teachers influence the academic achievement of students. From the investigation, the researcher established that teachers who did not engage in regular serving as most of the teachers attended seminars only once. Equally, almost half of the teachers did not attend any seminar in a period of two years. This implied that teachers lacked regular refresher courses to introduce them to new skills, knowledge needed in teaching due to the diverse way which likes to affect performance in a diverse way. The study recommended that relevant stakeholder should induct teachers to prepare them with new and relevant essential teaching expertise and knowledge. This is because the diverse experiences observed amongst teachers can also lead to diverse production of results on pupils. The study, however, leaves a gap as the researcher focused on the general performance of teachers whereas this study was narrowed to teaching of literacy skills.

\section{Methodology}

In this study, the researcher adopted descriptive survey design. The research design helped to provide the nitty gritty details about who, what and how the researcher undertook inquiries of the research evaluation on how the different teacher's experience may affect the development of literacy skills among primary school learners. Similarly, the investigator identified a survey design as being appropriate in this case by presuming that the selected sample has similar traits with the population with which they were derived (Rukwaru, 2020). Survey design was, therefore, useful in assembling current info on teacher issues that affect the development of literacy skills in primary school pupils in Mbaraki Zone, Mombasa County, Kenya.

The site for the study was in Mbaraki Zone. The zone is located in Mombasa County and was appropriate for the study due to the continued poor performance of learners in literacy (Mugo, Ruto, Nakabugo, \& Mgalla, 2015) as well as its poor performance in KCPE in the previous years. From Mbaraki Zone, Mombasa County, Kenya, the researcher targeted all the head teachers, pupils and teachers from twenty primary schools across the Zone. Grade one was chosen because it is a crucial stage where pupils are accorded the orientation to formal learning. 
In selecting primary schools from Mbaraki Zone, Mombasa County, the researcher adopted census sampling where all the primary schools were sampled. Census sampling was used to select the head teachers. Purposive sampling was used to sample grade one teachers in primary schools in Mbaraki Zone in Mombasa County, Kenya. On the other hand, simple random sampling was used to select three learners from grade one.

All the twenty primary schools in Mbaraki zone were included in the study. A census sample approach was used to obtain the sample for the primary schools, head teachers and purposive sampling was used to select grade one teachers because the number is relatively small, thus all formed the sample size for the study. In this case, the researcher targeted grade one teachers and the school head teachers. Therefore, purposive sampling was used to sample all the elements of the population; hence a census approach allowed the researcher to sample all the head teachers and grade one teachers in the zone. In every school, interviewed the head teacher, grade one teacher and randomly sampled three Grade one learners (three per teacher to reduce observation bias). Consequently, the sample size for the study was 180 participants. Table 1 presents the sample population and the sampling technique applied.

Table 1: Sample size

\begin{tabular}{|l|c|c|c|}
\hline Category & Target Total Number & Sampling Technique & Sample Size \\
\hline Head teachers & 20 & Census & 20 \\
\hline Teachers (20*2) & 40 & Purposive Sampling & 40 \\
\hline Children / Pupils $\left(20^{*} 40\right)$ & 800 & Simple Random Sampling & 120 \\
\hline Total & $\mathbf{8 6 0}$ & & $\mathbf{1 8 0}$ \\
\hline
\end{tabular}

Data was collected using questionnaire that were issued to the grade one teachers. Interview schedule for the Head Teachers also sought to understand the Head teachers' perceptions on whether teachers' experience influenced the teaching of literacy skills among Grade one learners. An Observation checklist was also used to collect data from Grade one learners. The observation checklist purposed to collect data on the grade one pupil's level of literacy skills development such as the pupil's reading, writing, listening, speaking and basics drawing and shading skills.

Data analysis was guided by the kind of data collected. The researcher used thematic or content analysis to work on the qualitative data. This was the data garnered from the interview schedules as well as the observation checklists. The researcher was seeking to identify the central themes and patterns from the respondent's responses and observations. These were recorded and analysed to ensure they were consistent, adequate and useful to the phenomenon under examination. In regard to the quantitative data, once collected, it was cleaned, coded and then analyzed using the Statistical Packages for Social Science (SPSS) software. Frequencies and percentages were obtained from the descriptive statistics of the responses provided. Data from the observation schedules was analyzed quantitatively where codes were assigned to the different aspects of literacy and abilities where able was coded as 1 and not able was 2 . It was analyzed descriptively to show the number of children who could read, write, listen, 
speak and do basic drawing and shading. Chi-square goodness of fit helped the researcher to determine whether an association existed between the teacher-related features and the teaching of literary skills. The chi squire was used to determine whether teacher factors: teacher's academic qualification, teaching experience, teacher's gender and workload influence the teaching of literacy skills. To present the results, the researcher used both tables and figures.

\section{Findings and Discussion}

\subsection{Grade One Learners' Literacy Skills}

The dependent variable in the study was grade one learners' literacy skills. The researcher observed 117 learners and averaged their literacy skills to get an average based on the class observed. The frequencies of the learners' literacy skills are as provided in Table 2.

Table 2: Literacy Skills Assessment

\begin{tabular}{|l|c|c|c|}
\hline Literacy Skill Assessment & N=39 & Able & Unable \\
\hline \multirow{2}{*}{ Can actively listen to a story. } & $\mathrm{F}$ & 15 & 24 \\
\cline { 2 - 4 } & $\%$ & 38.5 & 61.5 \\
\hline \multirow{2}{*}{ Can identify letters of the alphabet. } & $\mathrm{F}$ & 19 & 20 \\
\cline { 2 - 4 } & $\%$ & 48.7 & 51.3 \\
\hline \multirow{2}{*}{ Can identify missing letters of the alphabet. } & $\mathrm{F}$ & 14 & 25 \\
\cline { 2 - 4 } Can identify primary colors. & $\%$ & 35.9 & 64.1 \\
\hline \multirow{2}{*}{ Can read simple words correctly. } & $\mathrm{F}$ & 14 & 25 \\
\hline \multirow{2}{*}{ Can recognize own name. } & $\mathrm{F}$ & 35.9 & 64.1 \\
\hline \multirow{2}{*}{ Can re-tell a story. } & $\%$ & 25.6 & 29 \\
\hline \multirow{2}{*}{ Can tell own name. } & $\mathrm{F}$ & 17 & 74.4 \\
\cline { 2 - 4 } & $\%$ & 43.6 & 22 \\
\hline \multirow{2}{*}{ Can write his/her name. } & $\mathrm{F}$ & 9 & 36.4 \\
\hline \multirow{2}{*}{ Can write letters of the alphabet. } & $\%$ & 23.1 & 76.9 \\
\hline \multirow{2}{*}{ Can write simple words e.g. (cat, book, pen ) } & $\mathrm{F}$ & 29 & 10 \\
\cline { 2 - 4 } & $\%$ & 74.4 & 25.6 \\
\cline { 2 - 4 } & $\%$ & 24 & 15 \\
\cline { 2 - 4 } & $\mathrm{F}$ & 21.5 & 38.5 \\
\hline
\end{tabular}

Table 2 shows that the majority of learners $24(61.5 \%)$ were not able to actively listen to a story while only $15(38.5 \%)$ were able to actively listen to a story. The findings imply that most of the grade one learners were not able to actively listen to a story.

In regard to the learners' ability to identify letters of the alphabet, the majority of the learners $20(51.3 \%)$ were not able to identify the letters while most $19(48.7 \%)$ of the 
learners were able to identify letters of the alphabet. These findings imply that most of the learners could identify the letters of the alphabet. The researcher further observed whether the learners could identify missing letters of the alphabet. It was found that the majority of the learners $25(64.1 \%$ ) were not able to identify the missing letters of the alphabet while only $14(35.9 \%)$ were able to identify the missing letters of the alphabet. These findings imply that though most learners could identify the letters of the alphabet, most could not fill in the letters of the alphabet.

The table further shows that learners were observed to be unable to read simple words $29(74.44 \%)$ while $10(25.6 \%)$ were able to read simple words. These findings imply that the majority of the learners in the classes observed could not read simple words correctly.

The researcher also observed whether the learners could recognize their own name and observed that most 22(56.4\%) of the learners could not identify their own names while $17(43.6 \%)$ could not identify their own name. These findings imply that most leaners could not identify their own names. However, it was observed that the majority of the learners $29(74.4 \%)$ were able to tell their own name while a minority $10(25.6 \%)$ were found not to be in a position to tell their own name.

The researcher further observed that the majority of the respondents $30(76.9 \%)$ were not able to re-tell a story while only $9(23.1 \%)$ were able to re-tell a story. Moreover, the majority of the respondents $24(61.5 \%)$ were able to write his or her name with a minority $15(38.5 \%)$ indicating that they could not write his or her name. In regard to the letters of the alphabet, the majority $21(53.8 \%)$ could write the letters of the alphabet while $18(46.2 \%)$ could not write the letters of alphabet. It was also found that the majority of the learners $25(64.1 \%)$ could not write simple words while a minority $14(35.9 \%)$ were found to be able to write simple words. These findings suggest that most of the grade one leaners observed were not able to re-tell a story and most were also able to write their own names. However, a minority were not able to write simple words despite knowing how to write the letters of the alphabet.

In order to conduct the inferential statistics, the eleven aspects of literacy were computed into five major aspects of literacy skills; reading, listening, speaking, basics and writing. The computed findings are as presented in Table 3.

Table 3: Literacy Skills

\begin{tabular}{|l|l|l|l|}
\hline Literacy Skill & $\mathbf{N}=\mathbf{3 9}$ & $\mathbf{F}$ & $\mathbf{\%}$ \\
\hline \multirow{2}{*}{ Writing } & Able & 21 & 61.5 \\
\cline { 2 - 4 } & Not Able & 15 & 38.5 \\
\hline \multirow{2}{*}{ Reading } & Able & 13 & 33.3 \\
\cline { 2 - 4 } & Not Able & 26 & 66.7 \\
\hline \multirow{2}{*}{ Speaking } & Able & 11 & 28.2 \\
\cline { 2 - 4 } & Not Able & 28 & 71.8 \\
\hline \multirow{2}{*}{ Listening } & Able & 9 & 23.1 \\
\cline { 2 - 4 } & Not Able & 30 & 76.9 \\
\hline \multirow{2}{*}{ Basic } & Able & 12 & 30.8 \\
\cline { 2 - 4 } & Not Able & 27 & 69.2 \\
\hline
\end{tabular}


As Table 3 shows, the majority of the learners $24(61.5 \%)$ were able to write while $15(38.5 \%)$ were not able to write. However, the majority of learners $26(66.7 \%)$ were not able to read, just as the majority $28(71.8 \%)$ were not able to portray speaking skills while $30(76.9 \%)$ were not able to portray listening skills and $9(23.1 \%)$ were not able listen. Lastly, it was observed that most learners 27(69.2\%) lacked basic skills such as identifying primary colours.

Overall, these findings suggest that the majority of learners were not able to read, listen, speak or show basic skills. It can, therefore, be deduced that the learners could write their names and the letters of the alphabet, but could not read simple words, identify missing letters of the alphabet and could not identify primary colours.

\subsection{Teachers' teaching Experience and Literacy Skills}

The study purposed to determine how the teachers' teaching experience influenced their teaching of literacy skills among grade one learners. So, the teachers were asked to indicate the number of years they have served in their current position. Their responses are as provided in Figure 1.

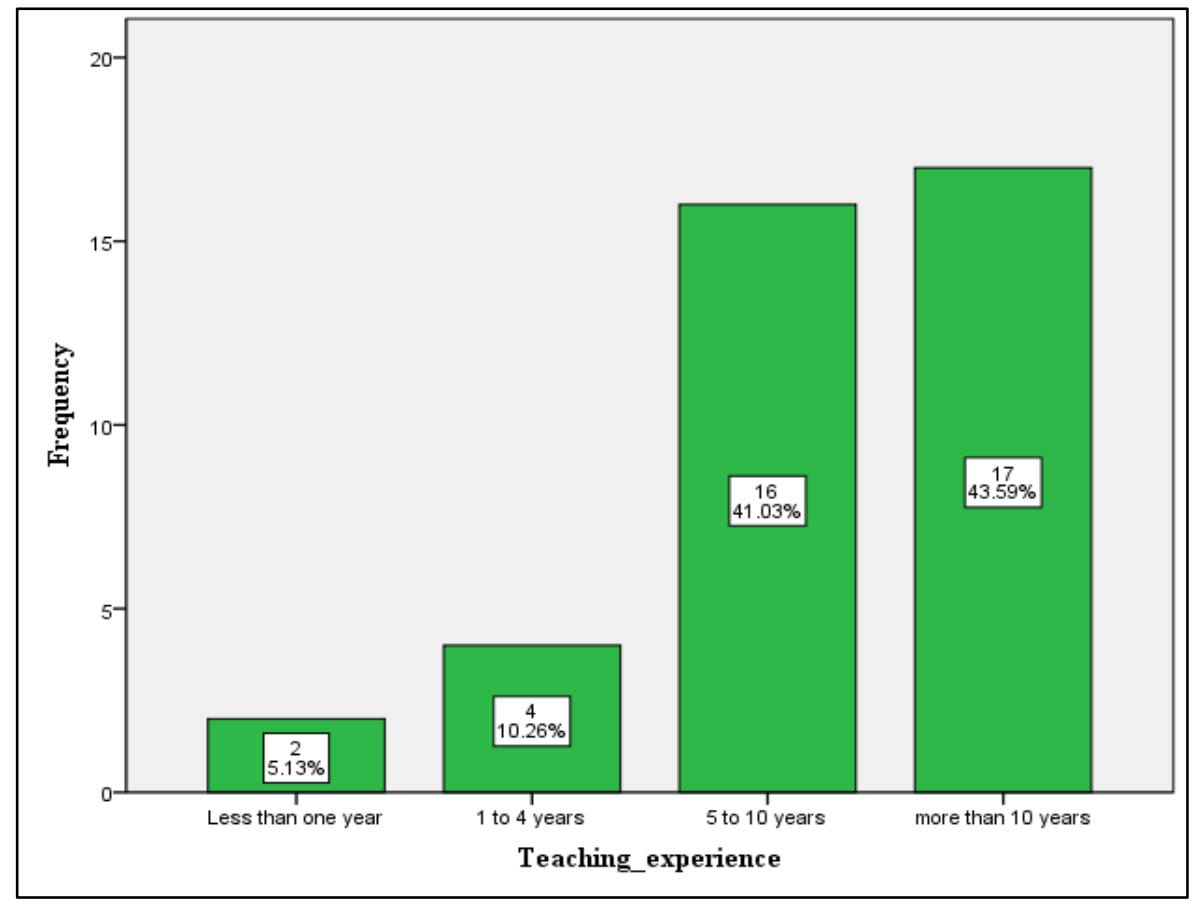

Figure 1: Teaching Experience

As Figure 1 shows, the majority of the respondents 17(43.59\%) indicated that they had taught for more than ten years, $16(41.03 \%$ ) while a minority $4(10.26 \%)$ indicated that they had taught for between one and four years with only $2(5.13 \%)$ indicating that they had taught for less than one year. These findings imply that the majority of the teachers had more than five years of experience teaching suggesting that they should be more adept at teaching literacy skills. Contrary, the interview findings revealed that that in some cases, this is not true. 
"Not true as teacher would be doing the same thing year in year out without change in output or constructive feedback from Administration recommending professional development."

Contrary, Dana (2014) argued that teachers are able to improve on their content, teaching methods and solving problems when they continuously engage in teaching. Bearing in mind that prior exposure can be inferred is useful for teachers when disseminating new knowledge to the pupils. Their confidence is always improved with the exposure and experience they acquire.

The researcher then sought to examine whether the teachers' level of qualification had an influence on the teaching of literacy skills among grade one learners. The findings are provided in Table 4 .

Table 4: Chi-Square Analysis- Academic Qualification and Literacy Skills

\begin{tabular}{|c|c|c|c|c|c|c|c|}
\hline & \multicolumn{5}{|c|}{ Experience } & \multirow{2}{*}{$P$ value } \\
\hline & & $\mathrm{N}=39$ & $<1$ year & 1-4 years & $5-10$ years & $>10$ years & \\
\hline \multirow{4}{*}{ Writing } & \multirow{2}{*}{ Able } & $\mathrm{F}$ & 1 & 2 & 10 & 11 & \multirow{4}{*}{0.937} \\
\hline & & $\%$ & 2.56 & 5.13 & 25.64 & 28.21 & \\
\hline & \multirow{2}{*}{ Not Able } & $\mathrm{F}$ & 1 & 2 & 6 & 6 & \\
\hline & & $\%$ & 2.56 & 5.13 & 15.38 & 15.38 & \\
\hline \multirow{4}{*}{ Reading } & \multirow{2}{*}{ Able } & $\mathrm{F}$ & 0 & 3 & 6 & 4 & \multirow{4}{*}{0.014} \\
\hline & & $\%$ & 0 & 7.69 & 10.26 & 10.26 & \\
\hline & \multirow{2}{*}{ Not Able } & $F$ & 2 & 1 & 10 & 13 & \\
\hline & & $\%$ & 5.13 & 2.56 & 25.64 & 33.33 & \\
\hline \multirow{4}{*}{ Speaking } & \multirow{2}{*}{ Able } & $F$ & 0 & 0 & 7 & 4 & \multirow{4}{*}{0.021} \\
\hline & & $\%$ & 0 & 0 & 17.95 & 10.26 & \\
\hline & \multirow{2}{*}{ Not Able } & $\mathrm{F}$ & 2 & 4 & 9 & 13 & \\
\hline & & $\%$ & 5.13 & 10.26 & 23.08 & 33.33 & \\
\hline \multirow{4}{*}{ Listening } & \multirow{2}{*}{ Able } & $\mathrm{F}$ & 0 & 1 & 3 & 5 & \multirow{4}{*}{0.038} \\
\hline & & $\%$ & 0 & 2.56 & 7.69 & 12.82 & \\
\hline & \multirow{2}{*}{ Not Able } & $\mathrm{F}$ & 2 & 3 & 13 & 12 & \\
\hline & & $\%$ & 5.13 & 7.69 & 33.33 & 30.77 & \\
\hline \multirow{4}{*}{ Basic Skills } & \multirow{2}{*}{ Able } & $\mathrm{F}$ & 1 & 2 & 4 & 5 & \multirow{4}{*}{0.019} \\
\hline & & $\%$ & 2.56 & 5.13 & 10.26 & 12.82 & \\
\hline & \multirow{2}{*}{ Not Able } & $F$ & 1 & 2 & 12 & 12 & \\
\hline & & $\%$ & 2.56 & 5.13 & 30.77 & 30.77 & \\
\hline
\end{tabular}

In Table 4, the majority of the teachers $11(28.21 \%)$ who had more than ten years of experience were those with learners who were able to write while the teachers with less than one years' experience $1(2.56 \%$ ) had learners who were unable to write. However, there was a lack of association between writing and the teachers' experience at $p$ value 0.0937. These findings concur with those by Dana (2014) who argued that prior exposure can be inferred and may be useful for teachers when disseminating new knowledge to the pupils. Their confidence is always improved with the exposure and experience they 
acquire. In this context, teacher's teaching experience can play a significant role in decision making and content delivery especially the literacy skill.

The table also shows that the majority of the teachers with between 6-10 years of experience $6(10.26 \%)$ had learners who were able to read while all of the learners $2(5.12 \%)$ who were unable to read were those whose teachers had less than one years' experience teaching. The findings imply that the teachers' experience influenced their teaching of reading skills where the $\mathrm{p}$ value $0.014<0.05$ shows that the teachers' experience had a significant impact on the likelihood of learners taught by experienced teachers being able to read. These findings are supported by the claims by the head teachers where one argued.

"Teaching experiences provide real life experiences and enhance the teachers' competencies with live situations. The opportunity for diversity in the learning experiences provides a rich learning experience by the teacher. The opportunity to try, see results, learn, reflect in a cyclical manner reinforces the learning opportunities."

These findings are supported by Dana (2014) who avers that teacher can improve their content, teaching methods and solving problems when they continuously engage in teaching. Bearing in mind that prior exposure can be inferred is useful for teachers when disseminating new knowledge to the pupils. Their confidence is always improved with the exposure and experience they acquire.

Further, it can be seen that the majority of learners $7(17.95 \%)$ and $4(10,26 \%)$ whose teachers had between six and ten years of experience and more than ten years of experience had learners who had speaking skills while all of the learners $2(5.13 \%)$ and $4(10.26 \%)$ whose teachers had less than five years of experience lacked speaking skills. The $\mathrm{p}$ value 0.021 shows that the teachers' level of experience had a statistically significant influence on the teaching of speaking skills suggesting that teachers with more experience are likely to teach learners speaking skills better than those with less experience. The head teachers further supported the findings during the interview where one argued that though not all teacher experiences make them competent and effective, but this is best realized when the teacher is prepared to meet the desirable competency standards. Moreover, experience helps a lot thus an experienced teacher understands different teaching methods and different learning approach unlike a teacher who is the vice versa. As Ewetan (2015) found, teaching experience that teachers possessed have significant influence on how students performed academically in the two subjects under examination. This is because as teachers got more teaching experience, they tended to achieve better results as compared to the schools where their teachers were still new to their careers and had accumulated less teaching experience.

In regard to listening skills, the $\mathrm{p}$ value 0.038 shows that there is a statistically significant association between the teachers' experience and the learners' listening skills where the majority $5(12.82 \%)$ of the teachers with more than 10 years experience had learners who were able to listen while the teachers with less than one years of experience 
had only one learner who was able to listen. This implies that teachers with more experience were likely to effectively teach learners listening skills as compared to those with less experience. these findings support claims made by Wildova and Kropáčková, (2015) who contends that teacher experience is likely to affect their teaching which may consequently lead to poor academic performance of pupils.

Last, the table also shows that the majority of learners who portrayed basic skills $5(12.82 \%)$ were those whose teachers had more than ten years of experience while the majority of those with between six-10 years of experience $12(30.77 \%)$ had no basic skills implying that there was an association between the teachers' teaching experience and the teaching of basic skills as seen in the statistically significant $p$ value 0.019 . Chokera (2014) also argued that having experience positively influences ones' execution of duties.

\title{
6. Conclusion and Recommendations
}

The second objective of the study purposed to examine how the teacher's teaching experience influences the teaching of literacy skills among grade one pupils. It was found that the majority of the teachers had received in service training and some had gone to seminars and workshops. Further, the study findings revealed that the majority of teachers had more than five years of experience teaching literacy skills. The inferential analysis revealed that the teaching experience had a statistically significant influence on reading $(p 0.014)$, speaking ( $(p 0.021)$, listening skills $(p 0.038)$, basic skills ( $(p 0.019)$.

So, the study concludes that the teachers' teaching experience had a statistically significant influence on teaching of literacy skills. The study calls on the ministry of education and the schools to ensure that teachers assigned to grade one should have extensive experience teaching literacy skills to promote teaching of literacy skills in the classes.

\section{Conflict of Interest Statement}

I have no conflict of interest to declare.

\begin{abstract}
About the Author
Emelda Juma Olando is currently a grade 2 homeroom teacher at Aga Khan Academy, Junior School, Nairobi since 2018, pursuing Master's Degree in education, Early Childhood Education, after receiving a Bachelor's Degree in Early Childhood and Primary Education at Moi University (2014). She holds a diploma from Kenyatta University and Certificate in Early Childhood Education 2009 and 2017 respectively. She is enthusiastic with literacy skills development in early years, and this is evidenced in her story publication by Moran Publishers in 2013.

Dr. Margaret Mwangi is Emelda Juma Olando's project supervisor at Kenyatta University, Kenya. She lectures students at the school of education, Early Childhood and Special Needs Education Department. She has worked at Kenyatta University since 2010.
\end{abstract}




\section{References}

Chokera, F., Ngwenya, T., \& Njovo, M. (2014). The role of agricultural marketing on empowering rural farmers in Masvingo Province, Zimbabwe. European Journal of Business and Management, 6(3), 153-163.

Ewetan, T. O., \& Ewetan, O. O. (2015). Teachers' Teaching Experience and Academic Performance in Mathematics and English Language in Public Secondary Schools in Ogun State, Nigeria. International Journal of Humanities, Social Sciences and Education, 2(2), 123-134.

Hamre, B., Hatfield, B., Pianta, R., \& Jamil, F. (2014). Evidence for general and domainspecific elements of teacher-child interactions: Associations with preschool children's development. Child development, 85(3), 1257-1274.

Hopps-Wallis, K., \& Perry, B. (2017). 'You can't Write that': The Challenges of Written Communication between Preschools and Schools. Australasian Journal of Early Childhood, 42(3), 22-30.

Jones, D. E., Greenberg, M., \& Crowley, M. (2015). Early social-emotional functioning and public health: The relationship between kindergarten social competence and future wellness. American journal of public health, 105(11), 2283-2290.

Kolb, D. A. (2014). Experiential learning: Experience as the source of learning and development. FT press.

Mugo, J. K., Ruto, S. J., Nakabugo, M. G., \& Mgalla, Z. (2015). A call to learning focus in East Africa: Uwezo's measurement of learning in Kenya, Tanzania and Uganda. Africa Education Review, 12(1), 48-66.

Mwoma, T. (2017). Children's reading ability in early primary schooling: Challenges for a Kenyan rural community. Issues in Educational Research, 27(2), 347-364.

Ogetange, B. T. (2018). Influence of school contextual dynamics on acquisition of reading skills among standard three pupils in Kisii County, Kenya. Unpublished doctoral thesis. Kenyatta University, Nairobi, Kenya.

Opletalova, A. (2015). Financial education and financial literacy in the Czech education system. Procedia-Social and Behavioral Sciences, 171, 1176-1184.

Reid Lyon, G., \& Weiser, B. (2009). Teacher knowledge, instructional expertise, and the development of reading proficiency. Journal of learning disabilities, 42(5), 475-480.

Rukwaru, M. (2020). Social Etiquette and Manners. Eureka Publishers.

Uwezo, T. (2011). Are our children learning? Annual learning assessment report. Annual Learning Assessment, Nairobi, Kenya, George Bensons Media Issue.

Wambiri, G. N., \& Ndani, M. N. (2015). Relative Contributions of Caregivers' Level of Education, Role Definition and Average Household Income to Caregiver Involvement in Children's Emergent Reading. Journal of Education and Practice, 6(24), 108-115.

Wildova, R., \& Kropáčková, J. (2015). Early childhood pre-reading literacy development. Procedia-Social and Behavioral Sciences, 191, 878-883. 

to copy, distribute, transmit or adapt the article content, providing a proper, prominent and unambiguous attribution to the authors in a manner that makes clear that the materials are being reused under permission of a Creative Commons License. Views, opinions and conclusions expressed in this research article are views, opinions and conclusions of the author(s). Open Access Publishing Group and European Journal of Education Studies shall not be responsible or answerable for any loss, damage or liability caused in relation to/arising out of conflicts of interest, copyright violations and inappropriate or inaccurate use of any kind content related or integrated into the research work. All the published works are meeting the Open Access Publishing requirements and can be freely accessed, shared, modified, distributed and used in educational, commercial and non-commercial purposes under a Creative Commons Attribution 4.0 International License (CC BY 4.0). 